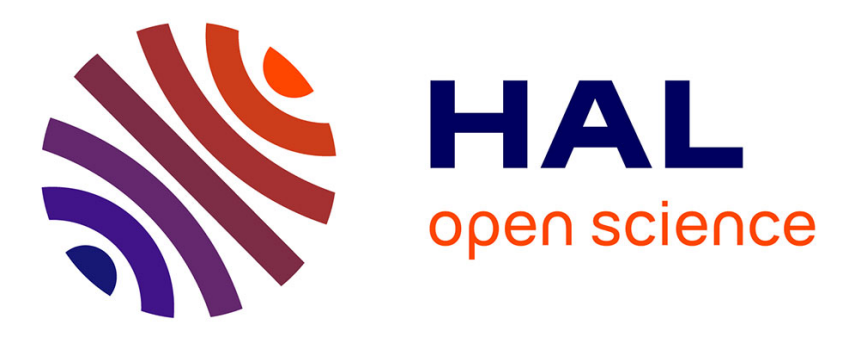

\title{
Dry-Etching Processes for High-Aspect-Ratio Features with Sub-10 nm Resolution High- $\chi$ Block Copolymers
}

Gwenaelle Pound-Lana, Philippe Bézard, Camille Petit-Etienne, Sébastien

Cavalaglio, Gilles Cunge, Benjamin Cabannes-Boué, Guillaume Fleury, Xavier

Chevalier, Marc Zelsmann

\section{To cite this version:}

Gwenaelle Pound-Lana, Philippe Bézard, Camille Petit-Etienne, Sébastien Cavalaglio, Gilles Cunge, et al.. Dry-Etching Processes for High-Aspect-Ratio Features with Sub-10 nm Resolution High- $\chi$ Block Copolymers. ACS Applied Materials \& Interfaces, 2021, 13 (41), pp.49184-49193. 10.1021/acsami.1c13503 . hal-03419581

\section{HAL Id: hal-03419581 \\ https://hal.science/hal-03419581}

Submitted on 15 Nov 2021

HAL is a multi-disciplinary open access archive for the deposit and dissemination of scientific research documents, whether they are published or not. The documents may come from teaching and research institutions in France or abroad, or from public or private research centers.
L'archive ouverte pluridisciplinaire HAL, est destinée au dépôt et à la diffusion de documents scientifiques de niveau recherche, publiés ou non, émanant des établissements d'enseignement et de recherche français ou étrangers, des laboratoires publics ou privés. 


\title{
Dry-etching processes for high aspect-ratio features with sub-10 $\mathrm{nm}$ resolution high- $\chi$ block copolymers
}

\author{
Gwenaelle Pound-Lana, ${ }^{1, *}$ Philippe Bézard, ${ }^{1, \dagger}$ Camille Petit-Etienne, ${ }^{1}$ Sébastien Cavalaglio, ${ }^{1}$ Gilles \\ Cunge, ${ }^{1}$ Benjamin Cabannes-Boué, ${ }^{2}$ Guillaume Fleury, ${ }^{2}$ Xavier Chevalier, ${ }^{3, *}$ and Marc Zelsmann ${ }^{1, *}$
}

\author{
1 Univ. Grenoble Alpes, CNRS, CEA/LETI Minatec, Grenoble INP, LTM, 38000 Grenoble, France. \\ 2 Univ. Bordeaux, CNRS, Bordeaux INP, LCPO, UMR 5629, F-33600, Pessac, France. \\ 3 ARKEMA FRANCE, GRL, Route Nationale 117, BP34 64170 Lacq, France.
}

KEYWORDS: lithography, Directed Self-Assembly (DSA), block copolymers, plasma dry etching, nanofabrication.

\begin{abstract}
Directed self-assembly of block copolymers (BCP) is a very attractive technique for the realization of functional nanostructures at high resolution. In this work, we developed full dry-etching strategies for BCP nanolithography using an 18-nm pitch lamellar silicon-containing block copolymer. Both an oxidizing $\mathrm{Ar} / \mathrm{O}_{2}$ plasma and a non-oxidizing $\mathrm{H}_{2} / \mathrm{N}_{2}$ plasma are used to remove the topcoat material of our BCP stack and reveal the perpendicular lamellae. Under $\mathrm{Ar} / \mathrm{O}_{2}$ plasma, an interfacial layer stops the etch process at the top-coat/BCP interface, which provides an etch-stop but also requires an additional $\mathrm{CF}_{4}$-based breakthrough plasma for further etching. This interfacial layer is not present in $\mathrm{H}_{2} / \mathrm{N}_{2}$. Increasing the $\mathrm{H}_{2} / \mathrm{N}_{2}$ ratio leads to more profound modifications of the silicon-containing lamellas, for which a chemistry in $\mathrm{He} / \mathrm{N}_{2} / \mathrm{O}_{2}$ rather than $\mathrm{Ar} / \mathrm{O}_{2}$ plasma produces a smoother and more regular lithographic mask. Finally, these features are successfully transferred into silicon, silicon-on-insulator and silicon nitride substrates. This work highlights the performance of a silicon-containing block-copolymer at $18 \mathrm{~nm}$ pitch to pattern relevant hardmask materials for various applications, including microelectronics.
\end{abstract}

\section{INTRODUCTION}

The downscaling of pattern dimensions in microelectronics has long passed the limits of $193 \mathrm{~nm}$ immersion lithography. Design-technology co-optimization (DTCO) ${ }^{1}$ allowed manufacturers to keep the pace in pitch scaling for the past decade, waiting for extreme-UV (EUV) lithography to become highvolume production-ready. The steady progress brought the pitches of the densest structures in the current most advanced CMOS nodes down to around $30 \mathrm{~nm}$. Future nodes will bring these pitches closer to $20 \mathrm{~nm}$ or below, which is beyond the limit of single exposure low-numerical aperture EUV lithography and thus, EUV-based multiple patterning schemes, ${ }^{2}$ such as self-aligned double patterning or self-aligned litho-etch-lithoetch will have to be introduced already.

Directed self-assembly (DSA) of block copolymers (BCPs) is an interesting candidate for advanced patterning in microelectronics due to its ability to produce lines/spaces or pillars at pitches which would otherwise require multiple low-NA exposures and masks. ${ }^{3}$ DSA is particularly attractive for the first metal levels in sub-3 nm nodes, where pitches are in the range of 20-30 nm, which is still reachable by low- $\chi$ BCP systems, such as PS- $b$-PMMA. ${ }^{4}$ However, the so-called "high- $\chi$ " BCPs, where the Flory-Huggins interaction parameter " $\chi$ " refers to the segregation strength between blocks, can reach pitches below
$22 \mathrm{~nm}$ without expensive double-patterning EUV process flows or future high-numerical aperture EUV lithography.

High- $\chi$ BCPs have been developed for their inherent ability to phase-segregate into thermodynamically favorable domains with at least one dimension below $10 \mathrm{~nm}$ and as low as $3 \mathrm{~nm} .^{5}$ Specific combinations of chemical composition, co-monomer ratio, molar mass and thermal treatment can be found to produce a variety of highly ordered systems among which the lamellar system is of great interest for line/space applications. ${ }^{6}$ The block copolymer is typically spin-coated on the planar substrate and one of its blocks is selectively removed after the phase-separation process so that the remaining block forms a lithographic mask on the substrate. In order to orient the features perpendicularly to the substrate, the block copolymer is sandwiched between neutral layers, namely a neutral underlayer (UL) and a neutral top coat (TC). Such materials present balanced affinity for either blocks and therefore provide a thermodynamic driving force to promote perpendicular orientation of the nanodomains. $^{7,8}$

We recently demonstrated the perpendicular orientation of lamellar high- $\chi$ BCP systems based on poly (1,1-dimethyl silacyclobutane)-block-polystyrene (PDMSB- $b$-PS), where the topinterface is neutralized using a functional chemically crosslinked top-coat material that enables breakthrough properties, such as patterning, dewetting cancelation and stacking of BCP 
films. ${ }^{7}$ PDMSB- $b$-PS combines two main advantages for highresolution nanolithography via DSA. Compared to the widely used PS- $b$-PMMA block copolymer, the higher segregation strength of PDMSB- $b$-PS $\left(\chi=0.07^{9}\right.$ vs 0.03 ) enables self-assembled domains of PDMSB lamellae with critical dimensions as low as $6 \mathrm{~nm}$. Another crucial advantage of this BCP platform is the inherent chemical contrast provided by the semi-organic nature of the Si-containing PDMSB block with respect to the fully organic nature of the PS block and of the underlayer and topcoat materials. This improved chemical contrast was foreseen as a keystone in semi-organic $\mathrm{Si}$-containing $\mathrm{BCP}^{10}$ to reveal the PDMSB-based lithographic mask.

In this work, we extend on previously published work $^{7,11,12}$ and compare our most successful dry-etching strategies with a high-resolution ( $\mathrm{L}_{0}=18 \mathrm{~nm}$ ) PDMSB- $b$-PS high- $\chi$ BCP assembled in fingerprints (as a preliminary study for DSA via chemoepitaxy), and transfer the PDMSB-derived lamellae at high aspect ratios into substrates of interest for microelectronic applications, including silicon on insulator (SOI) and silicon nitride $(\mathrm{SiN})$.

\section{EXPERIMENTAL DETAILS}

\section{Materials}

All pattern transfer experiments were performed with an optimized trilayer stack of PDMSB- $b$-PS block copolymer sandwiched between a neutral underlayer and a crosslinked topcoat (NL/BCP/TC), referred to as the BCP stack. Upon thermal annealing, the PS and Si containing PDMSB blocks segregate into lamellar domains with $9 \mathrm{~nm}$ resolution and perpendicular orientation with respect to the substrate. Further details on the neutral underlayer, BCP and topcoat material, all provided by Arkema are available in the literature. ${ }^{7}$ The BCP stack was assembled on $27 \times 27 \mathrm{~mm}^{2}$ squares cleaved from $200 \mathrm{~mm}$ diameter wafers of [1,0,0]-oriented $\mathrm{Si} ; 300 \mathrm{~mm}$ wafers of SOI with $15 \mathrm{~nm} \mathrm{Si}$ on $20 \mathrm{~nm}$ PEALD $\mathrm{SiO}_{2}$ on $\mathrm{Si}$; or $300 \mathrm{~mm}$ wafers of $\mathrm{Si}_{3} \mathrm{~N}_{4}$ on $\mathrm{Si}$ with either $55 \mathrm{~nm} \mathrm{LPCVD} \mathrm{Si}_{3} \mathrm{~N}_{4}$ on $10 \mathrm{~nm} \mathrm{SiO}_{2}$ or $20 \mathrm{~nm}$ PECVD $\mathrm{Si}_{3} \mathrm{~N}_{4}$ on $\mathrm{Si}$, both referred to as "SiN" and "SiN on $\mathrm{Si}$ " substrates, respectively. SiN samples were previously coated with a $22 \mathrm{~nm}$ thick layer of spin on carbon (SOC) obtained by spin-coating (2000 rpm) a solution of NFC HM8102-9 (JSR Micro), previously diluted in PGMEA $(1: 3 \mathrm{v} / \mathrm{v})$ and thermally crosslinked at $260^{\circ} \mathrm{C}$ for $1 \mathrm{~min}$.

\section{Preparation of the polymer stack}

The neutral underlayer was first grafted on the substrate $(\mathrm{Si}$, SOI, or SOC on $\mathrm{SiN}$ ) surface by spin-coating a $1 \mathrm{wt} \%$ solution of hydroxy-terminated poly(alkyl acrylate) homopolymer in methyl isobutyl ketone (MIBK) at $700 \mathrm{rpm}$ followed by thermal grafting at $200^{\circ} \mathrm{C}$ for $75 \mathrm{~s}$. Non-grafted material was removed by rinsing with PGMEA under sonication for $10 \mathrm{~s}$, leaving the substrate interface covered with a $5 \mathrm{~nm}$ thick underlayer. The PDMSB- $b$-PS BCP (a $0.9 \mathrm{wt} \%$ solution in MIBK of poly $(1,1-$ dimethyl silacyclobutane)-block-poly(styrene) with lamellar morphology and an intrinsic period of $18 \mathrm{~nm}$ ) was spin-coated at $2000 \mathrm{rpm}$ and the solvent evaporated at $60{ }^{\circ} \mathrm{C}$ for $1 \mathrm{~min}$. The topcoat solution is composed of a statistical terpolymer of glycidyl methacrylate, 2-hydroxyl ethyl methacrylate and 2,2,2-trifluoro ethyl methacrylate (abbreviated "FGH" hereafter) at 2 $\mathrm{wt} \%$ and a thermal initiator at $0.2 \mathrm{wt} \%$ in a $90: 10 \mathrm{v} / \mathrm{v}$ mixture of ethanol and PGME. This topcoat solution was spin-coated on the BCP film at $2000 \mathrm{rpm}$ and cured at $90^{\circ} \mathrm{C}$ for $3 \mathrm{~min}$ to initiate the crosslinking reaction between glycidyl pendant groups in the FGH terpolymer. The crosslinking reaction continues during the thermal annealing step applied to allow phase segregation in the BCP film at $260{ }^{\circ} \mathrm{C}$ for $5 \mathrm{~min}$. Under our experimental conditions, the layer thicknesses determined by spectroscopic ellipsometry were approximately $5 \mathrm{~nm}, 35 \mathrm{~nm}$ and 50 $\mathrm{nm}$ for the underlayer, BCP and topcoat layers, respectively, resulting in a total thickness of the BCP stack of $88 \pm 2 \mathrm{~nm}$.

\section{Plasma etch}

Etching experiments were performed in a $300 \mathrm{~mm}$ AdvantEdge $^{\mathrm{TM}}$ MESA $^{\mathrm{TM}}$ Inductively Coupled Plasma (ICP) etch tool from Applied Materials with chamber walls made of yttrium oxide. The plasma source is a dual-coil TCP with $13.56 \mathrm{MHz}$ RF generators of $3000 \mathrm{~W}$ nominal power. The electrostatic chuck can be polarized with bias power up to $1.5 \mathrm{~kW}$. The reactor is equipped with the Pulsync ${ }^{\mathrm{TM}} \mathrm{RF}$ system, which allows pulsing of the source and bias power in a wide range of frequencies and duty cycles (from a few tens of hertz up to tens of kilohertz and from a few percent up to continuous wave plasma). The carrier wafer temperature and the reactor body are maintained at $60^{\circ} \mathrm{C}$ and $65^{\circ} \mathrm{C}$, respectively. More detail about the experimental set-up can be found in the litterature. ${ }^{13}$ Samples were patched on $300 \mathrm{~mm} \mathrm{Si}$ wafers with Kapton ${ }^{\circledR}$ adhesive tape. Chamber conditioning starts with a wafer-less clean: $\mathrm{NF}_{3} / \mathrm{Cl}_{2}$ for $45 \mathrm{~s}, \mathrm{Cl}_{2} / \mathrm{O}_{2} / \mathrm{Ar}$ for $45 \mathrm{~s}$, and $\mathrm{O}_{2}$ for $30 \mathrm{~s}$. For $\mathrm{H}_{2} / \mathrm{N}_{2}$ experiments, the clean is followed by a 300 s-long $\mathrm{H}_{2} / \mathrm{N}_{2}$ conditioning plasma on Si blanket wafer. Unless indicated otherwise, $\mathrm{N}_{2} / \mathrm{O}_{2} / \mathrm{He}$ plasma BCP etch was carried out after a carbon-coating of the chamber walls (40 s of $\mathrm{CH} 4$ plasma). Such coating may also be used during TC etching with $\mathrm{H}_{2} / \mathrm{N}_{2}$. After a process with C-coated walls, the chamber is systematically cleaned with $\mathrm{O}_{2}$ for $60 \mathrm{~s}$.

\section{Plasma etch conditions}

Plasma etch steps were applied to sequentially remove the topcoat material and topcoat-BCP layer interface, where applicable, selectively remove the PS phase and neutral underlayer while leaving the PDMSB lamellae, and transfer the resulting PDMSB-derived mask into the underlying substrate. The plasma gas composition and flow rates (in sccm), chamber pressure (mTorr), source and bias powers (hereafter referred to as $\mathrm{Ws}$ and $\mathrm{Wb}$, respectively, in $\mathrm{W}$ ) are specified in the results and discussion section of the manuscript and figure legends.

\section{Spectroscopic ellipsometry}

The thicknesses of the layers in the BCP stack were determined in reflection mode with a phase modulated spectroscopic ellipsometer (UVISEL, from Horiba Scientifc) on the spectral range $300-800 \mathrm{~nm}$. A trilayer model was created with material dispersion files fitted on single layers with a Cauchy absorbent model. Optical index and thickness are both fitted at each point of the curves, then taking into account an eventual modification of the optical index of the layer during processing. For the morphologies of masks with open lamellae, the thicknesses measured correspond to an average value on the sample, i.e. approximately half of the height for standing lamellae (assuming an opening rate of $50 \%$ ). 
Scanning electron microscopy and scanning transmission electron microscopy

Top-view SEM images were acquired on a Hitachi CD-SEM $\mathrm{H}-9300$ microscope operating at $0.5 \mathrm{kV}$ electron acceleration voltage with a $6 \mu \mathrm{A}$ current. Cross-section SEM images were acquired on a Hitachi S-5000 microscope at $30 \mathrm{kV}$ electron acceleration voltage with $15 \mathrm{nA}$ emission current or using a Helios 450S-FEI dual beam microscope at $25 \mathrm{kV}$. This latter equipment is also used for sample preparation and STEM imaging. A series of Pt protective layers were deposited on a $30 \mu \mathrm{m} \times 2 \mu \mathrm{m}$ surface area of the sample under electron beam $(5 \mathrm{kV}, 26 \mathrm{nA}$, approx. $200 \mathrm{~nm}$ of Pt deposited) followed by a $600 \mathrm{~nm}$ thick $\mathrm{Pt}$ protective layer under focused ion beam $(30 \mathrm{kV}, 0.43 \mathrm{nA})$. On pattern-transferred samples (inorganic materials) a thin carbon layer was deposited under electron beam prior to Pt to increase contrast. A $30 \mu \mathrm{m} \times 2 \mu \mathrm{m}$ specimen was then etched away from the substrate at a depth of approx. $4 \mu \mathrm{m}$, transferred to a grid via an omniprobe needle for mechanical manipulation and thinned under focused ion beam $(30 \mathrm{kV}$, decreasing emission current from $2.5 \mathrm{nA}$ to $80 \mathrm{pA}$ ) to approximately $100 \mathrm{~nm}$ width. Transmission images of the cross-section were finally recorded in scanning mode at $29 \mathrm{kV}$ and $100 \mathrm{pA}$ on the same equipment using bright field detection.

\section{RESULTS AND DISCUSSIONS}

\section{Removal of cross-linked TCs}

Due to its cross-linked nature, the TC material is insoluble in solvents and thus cannot be removed through a simple rinsing step. Therefore, alternative strategies are required to remove the sacrificial TC layer and reveal the BCP film. Nevertheless, this is only a minor drawback considering the demonstrated benefits arising from the cross-linking properties such as patterning possibilities and dewetting anihilation. ${ }^{7}$ The methacrylic nature of the comonomers constituting the TC material makes it susceptible to depolymerization under UV-stimulus. We were thus able to achieve the TC removal via an "UV+wet" etch (Supporting information and Supporting Figure S1). Despite the efficiency of this method, we decided to show here more industrycompatible processes and propose alternative dry-etch developments for the removal of the TC material, under either oxidizing or reducing plasma-etch conditions.

\section{TC removal under oxidizing plasma conditions}

Dry-etch of the cross-linked TC material can be achieved with excellent selectivity with respect to the BCP under oxidizing plasmas conditions, owing to the improved chemical contrast between the two different materials. Indeed, the FGH material was designed to be entirely organic, therefore easily etched under oxidizing plasma conditions, e.g. a simple $\mathrm{O}_{2}$ plasma. In our case, an etch-stop is obtained on both PDMSB and PS phases of the BCP with an $\mathrm{Ar} / \mathrm{O}_{2}(80 / 40 \mathrm{sccm})$ plasma of $200 \mathrm{~W}$ source power and $20 \mathrm{~W}$ bias power (Figure 1). Once the etch process reaches the top of the BCP layer, the residual film thickness remains constant, at a value of $30-33 \mathrm{~nm}$, which corresponds to the thickness of the BCP and grafted underlayer (Figure 1). This point is corroborated by the almost featureless top-view SEM image after $35 \mathrm{~s}$ etch reported in Figure 1, where the typical fingerprints of the BCP are hardly visible, even with a $100 \%$ applied over-etch, and by cross-section SEM images after $8 \mathrm{~s}$ and $35 \mathrm{~s}$ etch (Figure $\mathrm{S} 2$ ). The $\mathrm{Ar} / \mathrm{O}_{2}$ plasma for TC removal is stopped right at the TC/BCP interface, most likely due to the formation of a silicon-rich layer located at the upper interface of the PDMSB- $b$-PS film, which etch mechanism is certainly limited to physical sputtering. Indeed, X-ray Photoelectron Spectroscopy (XPS) measurements (Figure S3), which probe the upper $7 \mathrm{~nm}$ of the layer, show a virtual absence of fluorine on the surface (and therefore a complete removal of the fluorinated TC), a strong presence of $\mathrm{Si}-\mathrm{O}, \mathrm{C}$ and $\mathrm{O}$ (indicating the presence of an oxidized layer of $\mathrm{SiO}_{\mathrm{x}} \mathrm{C}_{\mathrm{y}}$ type) as well as $\mathrm{Si}$ $\mathrm{C}$ and $\mathrm{C}-\mathrm{C}$ contributions (probably due to the signature of the $\mathrm{BCP}$ below); and this either after $25 \mathrm{~s}$ and $35 \mathrm{~s}$ of etching.

The origin of this silicon-rich layer at the TC/BCP interface is still under investigation. This layer may be due to a slightly imperfectly balanced TC composition (artificially enriching the upper interface of the BCP in PDMSB material), or to the presence of an interfacial mixing layer composed of TC and $\mathrm{BCP}$ material. The formation of a mixing layer during assembly of the BCP stack has been described in the literature for other BCP and TC compositions, and is related to the specific processes followed to obtain the functional $\mathrm{TC},{ }^{14}$ or to additives favoring the mixing of the two materials. ${ }^{15,16}$ Although it cannot be rigorously excluded, the latter seems unlikely in our case, since the TC was designed specifically to avoid diffusion of species between layers. Indeed, the present TC system presents different characteristics (low cross-linking temperature, oligomeric nature of its composition prior to the cross-linking step, or even orthogonality of the TC's solvent toward the BCP, etc...) limiting the diffusion of chemical species at the interface and a resultant interfacial mixing layer. It must be pointed out here that the potential silicon-rich layer would be extremely thin (much less than $5 \mathrm{~nm}$ ), since a continuous silicon-containing layer is not seen throughout the whole set of FIB-STEM characterizations.

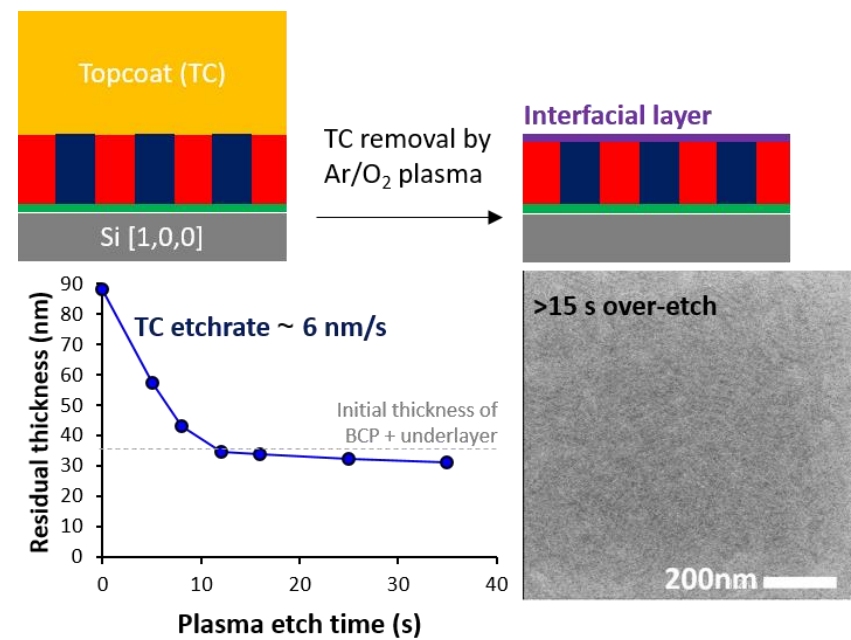

Figure 1: Dry etching of the organic cross-linked topcoat with an $\mathrm{Ar} / \mathrm{O}_{2}$ based plasma. Plasma etch conditions were: $\mathrm{Ar} 80 \mathrm{sccm}, \mathrm{O}_{2}$ $40 \mathrm{sccm}, 10 \mathrm{mT}, 200 \mathrm{Ws}, 20 \mathrm{~Wb}$. Residual thickness evolution vs etching time and SEM image of the surface after 30s etching.

More advanced characterization and processes would be required to further assess the origin and composition of the interfacial layer. Nonetheless, an explanation to the presence of an etch-stop here can be put forward, even though oxygen-based plasmas are later demonstrated to be chemically capable of etching the BCP. It is well-known that plasma etch forms a mixing layer of a few nm, mostly controlled by ion energy, where 
ions allow atoms buried under the surface of the material to be exposed to radicals. When this layer is composed of species with a large difference in reactivity towards plasma species (here silicon and carbon towards oxygen), renewal of the rapidly consumed species (here carbon) cannot compensate the losses and an enrichment of the mixing layer in the other species ensues (here silicon), thus forming a crust that protects the layer underneath from plasma etch. This etch-stop property is here obtained thanks to a relatively low bias power (low ion energy) and enables the etch process to stop exactly on the desired layer without deformation of the prepattern, and even enables an over-etch step to be performed on the stack to obtain clean interfaces. This property is extremely appealing for nano-fabrication with BCPs, enabling for instance new integration schemes involving top-coat patterning. ${ }^{7}$

Upon removal of the TC layer with the $\mathrm{Ar} / \mathrm{O}_{2}$ chemistry, a breakthrough step is performed in fluorocarbon chemistry in order to etch the oxidized silicon-rich interface. First attempts with a 5 s-long $\mathrm{CF}_{4} / \mathrm{O}_{2}$ plasma $\left(\mathrm{CF}_{4} 60 \mathrm{sccm}, \mathrm{O}_{2} 60 \mathrm{sccm}, 10\right.$ $\mathrm{mT}, 200 \mathrm{Ws}, 10 \mathrm{~Wb}$ ) also removed $\sim 5 \mathrm{~nm}$ of the BCP film. Following the BT step, the same $\mathrm{Ar} / \mathrm{O}_{2}$ plasma conditions as for TC removal are used to etch the PS phase of the BCP, as further evidenced by the increased contrast in SEM images. Although the $\mathrm{CF}_{4} / \mathrm{O}_{2}$ breakthrough step is efficient at removing the interfacial layer for further etching of the PS phase, broken lines are seen in the PDMSB mask after PS removal (Figure S4). In addition, the process window is narrow: a minimum of $5 \mathrm{~s}$ is required to remove the interface layer and $8 \mathrm{~s}$ produce significant damage to the PDMSB mask. Fluorocarbon-based chemistries are known to create a lot of stress on polymers (striations, etc.) due to the deposition of a fluorocarbon-rich layer, which thickness (typically 2-5 nm) cannot be neglected when etching lines of $\mathrm{CD} \sim 9 \mathrm{~nm} .{ }^{17}$ This stress affects the local density of the polymer material and thus its sensitivity to reactive species $(\mathrm{F}, \mathrm{O})$. It could explain the breaks appearing with longer process times.

Several attempts were made to prevent mask degradation, by tuning the nature and ratios of gases during the breakthrough process, and adjusting the bias/source powers applied accordingly. Significant improvement was achieved with respect to the $\mathrm{CF}_{4} / \mathrm{O}_{2}$ reference process via suppression of the oxygen component in the gas mixture and dilution of $\mathrm{CF}_{4}$ with an inert gas (He), which leads to a slower etch process, and thus to a better quality of the remaining mask even for a longer etch step (Figure S4). Further slowing-down of the interfacial etch process, through the progressive use of polymerizing fluorocarbon gas to dilute the $\mathrm{CF}_{4}$ component, and introduction of $\mathrm{N}_{2}$ as a mild fluorocarbon deposit etcher, improves the quality of the remaining $\mathrm{BCP}$ mask, at constant PS etch-rate. These are all clues that higher mask quality could be obtained through milder etch conditions, e.g. the use of chamber wall coating, reactor configuration, etc. However, due to the relatively tight processwindow obtained from our ICP reactor and despite our efforts and the improvement obtained, all ours attempts led to the introduction of defects in the self-assembled features (PDMSB broken lines), which prevented high-quality pattern transfer through this approach. Therefore, we investigated other plasma chemistries for the TC removal step, aiming at plasma etch conditions that improves the mechanical and/or chemical properties of the PDMSB material.

\section{TC removal under reducing plasma conditions}

The mixture of reductive gases based on $\mathrm{H}_{2} / \mathrm{N}_{2}$ chemistry is well-known for the stripping of photoresist material. ${ }^{18}$ When the $\mathrm{N}_{2}$ proportion is low $(<30 \%)$, the $\mathrm{H}_{2} / \mathrm{N}_{2}$ based plasma has large VUV fluence in the sub-200 $\mathrm{nm}$ wavelength range, while being a slow etcher for both silicon ${ }^{18}$ and PS. In addition, the VUV fluence is known to be efficient at cleaving $\mathrm{Si}-\mathrm{CH}_{\mathrm{x}}$ bonds, ${ }^{19} \mathrm{re}-$ sulting in a reduction in carbon content in the polymer, and thus a relative increase in the silicon content. This can be exploited as an additional curing process to reinforce both the etch and mechanical resistance of the PDMSB block, concomitantly to TC removal. In parallel, PS is promptly converted to hydrogenated amorphous carbon by destruction of its aromatic cycle. ${ }^{20}$ This amorphization is welcome in our case as it results in a much lower etch resistance when exposed to oxygen-based chemistries and thus larger selectivity with PDMSB when etching away the PS phase. As the TC is a fully organic methacrylate derivative, its etch rate is limited by the flux of atomic hydrogen. Indeed, increasing the nitrogen flux at the expense of $\mathrm{H}_{2}$ beyond the ratio used in our experiments results in a net drop of the etch rate, as the global amount of atomic $\mathrm{H}$ is diluted by nitrogen. It means that its ashing rate increases with pressure and ICP power. The VUV fluence however, owing to self-absorption by $\mathrm{H}_{2},{ }^{21}$ is larger at lower pressure, where the ion flux is also higher, and the atomic flux is proportionally lower. Considering our intent of modifying both the PS and the PDMSB, a slower etch rate of the topcoat is rather beneficial, although the larger ion flux reduces the selectivity with PS (severely ion-limited etch $\mathrm{rate}^{22}$ ). Provided the results observed on the effect of VUV on material modification during the etch process and that the limiting factor for etch-rate is the atomic hydrogen flux, we deduced that the etch rate will vary linearly with pressure and ICP power in the range of pressure and power relevant in the context. Therefore, a compromise was found at 15 mTorr to slow-down the TC etch rate $\left(\mathrm{H}_{2} 150 \mathrm{sccm}, \mathrm{N}_{2} 50 \mathrm{sccm}, 15 \mathrm{mT}\right.$, $1200 \mathrm{Ws}, 0 \mathrm{~Wb}$ ), resulting in $\sim 1.9 \mathrm{~nm} \cdot \mathrm{s}^{-1}$ etch rate for the TC and $\sim 1.1 \mathrm{~nm} \cdot \mathrm{s}^{-1}$ etch rate averaged for the both domains of the $\mathrm{BCP}$, thus leading to complete removal of the TC material within a comfortable $\sim 25-30 \mathrm{~s}$ process window (Figure 2A), easily tunable with the ICP power. Here, the interfacial layer is etched over a time lapse of $\sim 5 \mathrm{~s}$. If carbon-coating of the ICP chamber is used to slow down the etch mechanism, the TC etchrate decreases approx. 7-folds, and the time lapse for interfacial layer etch increases to approx. $30 \mathrm{~s}$ (Figure S5). This is expected due to the consumption of reactive species by the protective coating (reduction of the density of $\mathrm{O}$ atoms in the plasma by scavenging them to form $\mathrm{CO}$ and $\mathrm{CO}_{2}$ volatile products), resulting in reproducible etch rates and large process-windows.

In a similar manner, if the gas ratio is inverted to obtain a main $\mathrm{N}_{2}$ component over $\mathrm{H}_{2}$, such as a 97/3 ratio, the etch rate of the interfacial layer is slowed down by approx. $50 \%$, due to the depletion of the Si etchant in the gases mixture (Figure 2B). Thus, the gas ratio provides another leverage to precisely control the remaining thickness of the stack with an $\mathrm{N}_{2} / \mathrm{H}_{2}$ "etchslow" behavior. Reducing the $\mathrm{H}_{2}$ flow in order to induce a better etch-slow when reaching the interface layer however also reduces the curing effect on PDMSB (Si-enriching) and PS (hydrogenation and lowering of its etch resistance). 

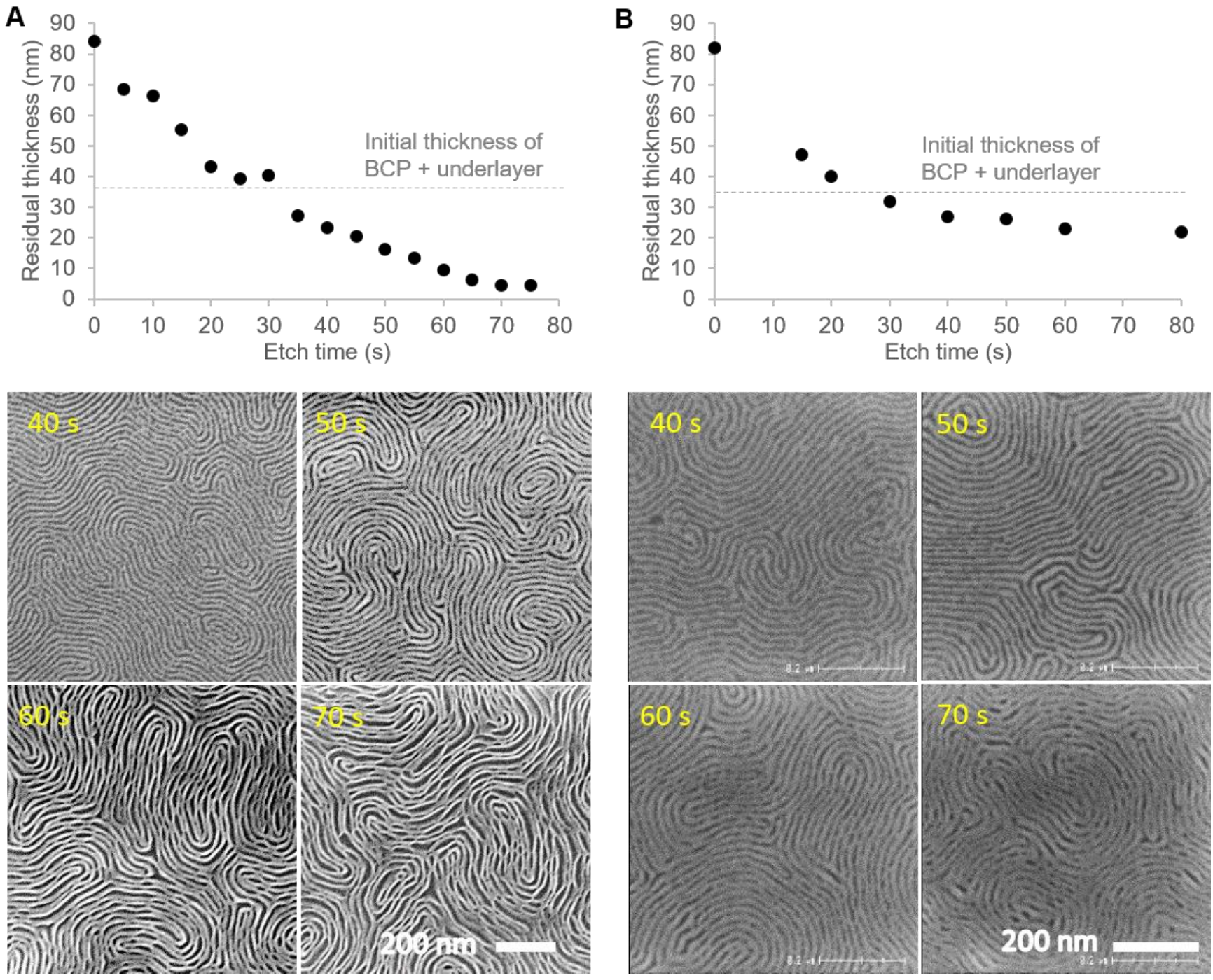

Figure 2: Comparison of remaining BCP stack thickness (top), and corresponding topview SEM images (below) following topcoat removal by non-oxidative plasma composed of $\mathrm{H}_{2}$ and $\mathrm{N}_{2}$ gases with (A) $\mathrm{H}_{2}$ excess $\left(\mathrm{H}_{2} 150 \mathrm{sccm}, \mathrm{N}_{2} 50 \mathrm{sccm}\right)$ and (B) $\mathrm{N}_{2}$ excess $\left(\mathrm{N}_{2} 97 \mathrm{sccm}, \mathrm{H}_{2} 3\right.$ sccm). SEM images show progressively enhanced contrast between PS (dark grey) and PDMSB (light grey) phases along with the etch time (indicated on each image), indicative of the absence of interfacial layer and progressive PS etch.

If either the $\mathrm{H}_{2} / \mathrm{N}_{2}(150 / 50 \mathrm{sccm})$ or the $\mathrm{N}_{2} / \mathrm{H}_{2}(97 / 3 \mathrm{sccm})$ plasma is further pursued, the contrast between the PDMSB and PS domains becomes more pronounced (Figure 2), indicating that the PS phase is etched faster than the PDMSB phase. However, in this case, the roughness of the PDMSB lamellae seems to increase, and significant bridge-defects can be seen on corresponding SEM (Figure 2) and cross-section SEM (Figure S6) images. This bridging effect might be due to a low kinetic of self-assembly, a slightly imbalanced surface energy of the underlayer or to physical re-deposition during the etch process. Moreover, there is a trade-off between consuming the PDMSB budget and fully opening the lithographic mask and we were not able to achieve further high quality pattern transfer, for example into the Si substrate, when using the same plasma chemistry for both TC and PS etch.
It should be mentioned that other groups already investigated a $\mathrm{N}_{2} / \mathrm{H}_{2}$ gas chemistry for the removal of the PS phase for their own high- $\chi$ BCP platform. ${ }^{23}$ The time duration over $10 \mathrm{~min}$ for their process is unfortunately excessively long to be considered as a viable pathway for high volume manufacturing with DSA. With the PDMSB- $b$-PS BCP, variable $\mathrm{N}_{2}$ ratios were tested (up to $50 \mathrm{sccm}$ and $500 \mathrm{sccm}$ for $\mathrm{H}_{2}$ and $\mathrm{N}_{2}$, respectively), and similar selectivities were observed as in our case, which also made pattern transfer into the substrate difficult. ${ }^{12}$ Finally, using large $\mathrm{H}_{2}$ process times is known to be detrimental for doping and electrical performances of a device in general: over-exposing the BCP to etch it in a single step here could damage logic layers underneath. These different drawbacks prompted us to investigate dedicated plasma etch strategies for the removal of the PS phase, depending on the TC etch plasma chemistries applied. 


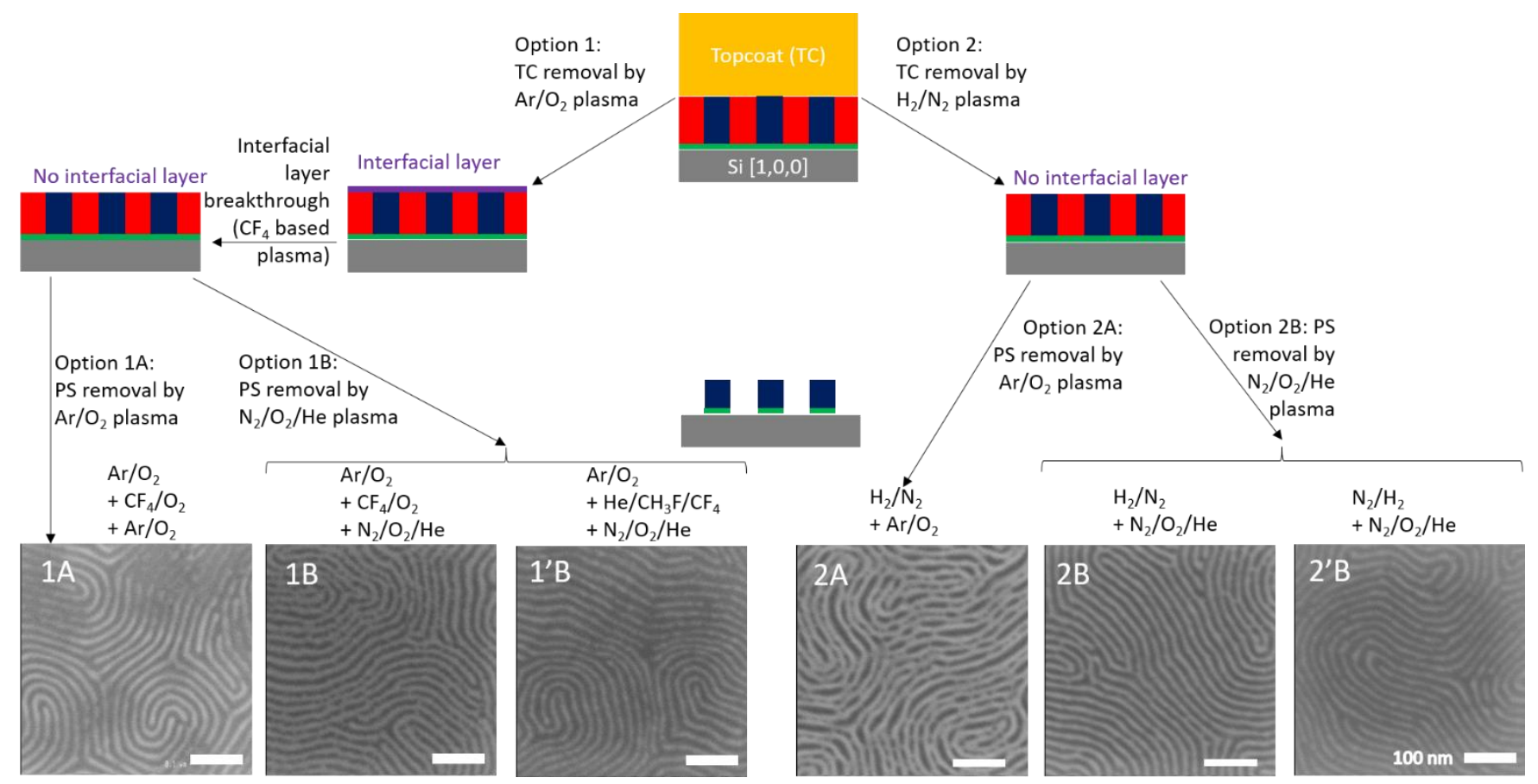

Figure 3: Comparison between the different topcoat and PS removal dry etching plasma conditions. The CDSEM images for evaluation of the PDMSB mask roughness and homogeneity were obtained on an annealed stack of BCP on Si submitted to full TC removal followed by partial PS removal. The plasma etch conditions were as follows: Ar/O2 plasma: Ar $80 \mathrm{sccm}, \mathrm{O}_{2} 40 \mathrm{sccm}, 10 \mathrm{mT}, 200 \mathrm{Ws}, 20 \mathrm{~Wb}, 35 \mathrm{~s}$ for TC removal, 5s for partial PS removal; $\mathrm{H}_{2} / \mathrm{N}_{2}$ plasma: $\mathrm{H}_{2} 150 \mathrm{sccm}, \mathrm{N}_{2} 50 \mathrm{sccm}, 15 \mathrm{mT}, 1200 \mathrm{Ws}, 0 \mathrm{~Wb}, 35 \mathrm{~s} ; \mathrm{N}_{2} / \mathrm{H}_{2}$ plasma: $\mathrm{N}_{2} 97 \mathrm{sccm}$, $\mathrm{H}_{2} 3 \mathrm{sccm}, 15 \mathrm{mT}, 1200 \mathrm{Ws}, 0 \mathrm{~Wb}, 35 \mathrm{~s} ; \mathrm{CF}_{4} / \mathrm{O}_{2} \mathrm{BT}: \mathrm{CF}_{4} 60 \mathrm{sccm}, \mathrm{O}_{2} 60 \mathrm{sccm}, 10 \mathrm{mT}, 200 \mathrm{Ws}, 10 \mathrm{~Wb}, 5 \mathrm{~s} ; \mathrm{soft} \mathrm{BT}: \mathrm{He} 80 \mathrm{sccm}, \mathrm{CH}_{3} \mathrm{~F} 20$ $\mathrm{sccm}, \mathrm{CF}_{4} 20 \mathrm{sccm}, 10 \mathrm{mT}, 600 \mathrm{Ws}, 60 \mathrm{~Wb}, 10 \mathrm{~s} ; \mathrm{He} / \mathrm{N}_{2} / \mathrm{O}_{2}$ plasma: $\mathrm{He} 100 \mathrm{sccm}, \mathrm{N}_{2} 35 \mathrm{sccm}, \mathrm{O}_{2} 15 \mathrm{sccm}, 10 \mathrm{mT}, 250 \mathrm{Ws}, 30 \mathrm{~Wb}, 15 \mathrm{~s} \mathrm{in}$ $\mathrm{CH}_{4}$-coated plasma chamber.

\section{PS removal options}

Removal of the PS phase can be performed with high selectivity with respect to the PDMSB phase of the $\mathrm{BCP}$, for instance with an $\mathrm{Ar} / \mathrm{O}_{2}$ based plasma. Etch experiments performed on blanket wafers of each component indicated etch rates of nearly $2.6 \mathrm{~nm} . \mathrm{s}^{-1}$ and $0.002 \mathrm{~nm} . \mathrm{s}^{-1}$, for PS and PDMSB homopolymers, respectively, under the same etch conditions as in our $\mathrm{Ar} / \mathrm{O}_{2}$ based TC removal approach (Ar $80 \mathrm{sccm}, \mathrm{O}_{2} 20 \mathrm{sccm}, 10 \mathrm{mT}$, $200 \mathrm{Ws}, 20 \mathrm{~Wb}$ ), and the increase in contrast due to the selective removal of the PS phase of the BCP is visible on SEM images (Figure 3). It is interesting to note that the PS phase of the BCP can be etched under the same conditions that resulted in an etchstop at the TC/BCP interface. This may be counter-intuitive but it is easily explained. During BCP etch, the plasma to which the PDMSB is exposed is locally much poorer in oxygen than in the case of homo-PDMSB etch, due to the consumption of oxygen species by the PS phase being etched. This results in a significantly slower consumption of the carbon atoms in PDMSB (less silicon-enrichment) and no interfacial crust formation. These micro-loading effects are often reported in the literature to be the root cause for the large discrepancies in selectivity measurements between blanket (homopolymers) and patterned (BCP) wafers. ${ }^{24,25}$

After PS removal by $\mathrm{Ar} / \mathrm{O}_{2}$ etch, the revealed PDMSB patterns showed high line roughness, bridges and some pattern collapse (SEM image 2A in Figure 3), which prompted us to reduce the plasma selectivity between both blocks in order to keep the aspect ratio lower $(<3: 1)$ and smoothen the PDMSB features. PS, even once hydrogenated, is etched by chemical sputtering and the etch rate is strongly ion-limited. PDMSB however, builds up a protective silicon-rich crust (as evidenced in Figure S7) when the reactivity of the plasma species with carbon is too high (ions also bring heat, which according to Arrhenius Law, increases the reactivity of $\mathrm{O}$ with $\mathrm{C}$ ). By reducing the ion flux, the etch rate of PS also decreases and the Si-rich layer struggles to form on top of PDMSB, allowing it to be etched by $\mathrm{O}$ radicals. These considerations were taken into account to modify the PS etch plasma as follows: Ar (very efficient at producing ions) is replaced by $\mathrm{N}_{2}$ (which also increases the $\mathrm{O}$ radical flux), while $\mathrm{He}$ is used for dilution purposes (owing to its very low mass the ion flux of He is typically half that of $\mathrm{Ar}^{26}$ ). The enhancement of the chemical aspect by mixing $\mathrm{N}_{2}$ with $\mathrm{O}_{2}$ increases the lateral etch rate of PDMSB, thereby smoothening the lines that otherwise exhibit high roughness with Ar-based mixtures. ${ }^{27}$ Finally, carbon-coating of the chamber walls further decreases the etch-rate by a factor of about 2 (Figure 4 , top), thus providing a comfortable $25-35$ s process-window for complete removal of the PS-phase with this $\mathrm{He} / \mathrm{N}_{2} / \mathrm{O}_{2}$ plasma. Indeed, as evidenced by the SEM images reported in Figure 4, smooth PDMSB lamellas are obtained in this case and a PS vs PDMSB etch selectivity of about 2 is found. 


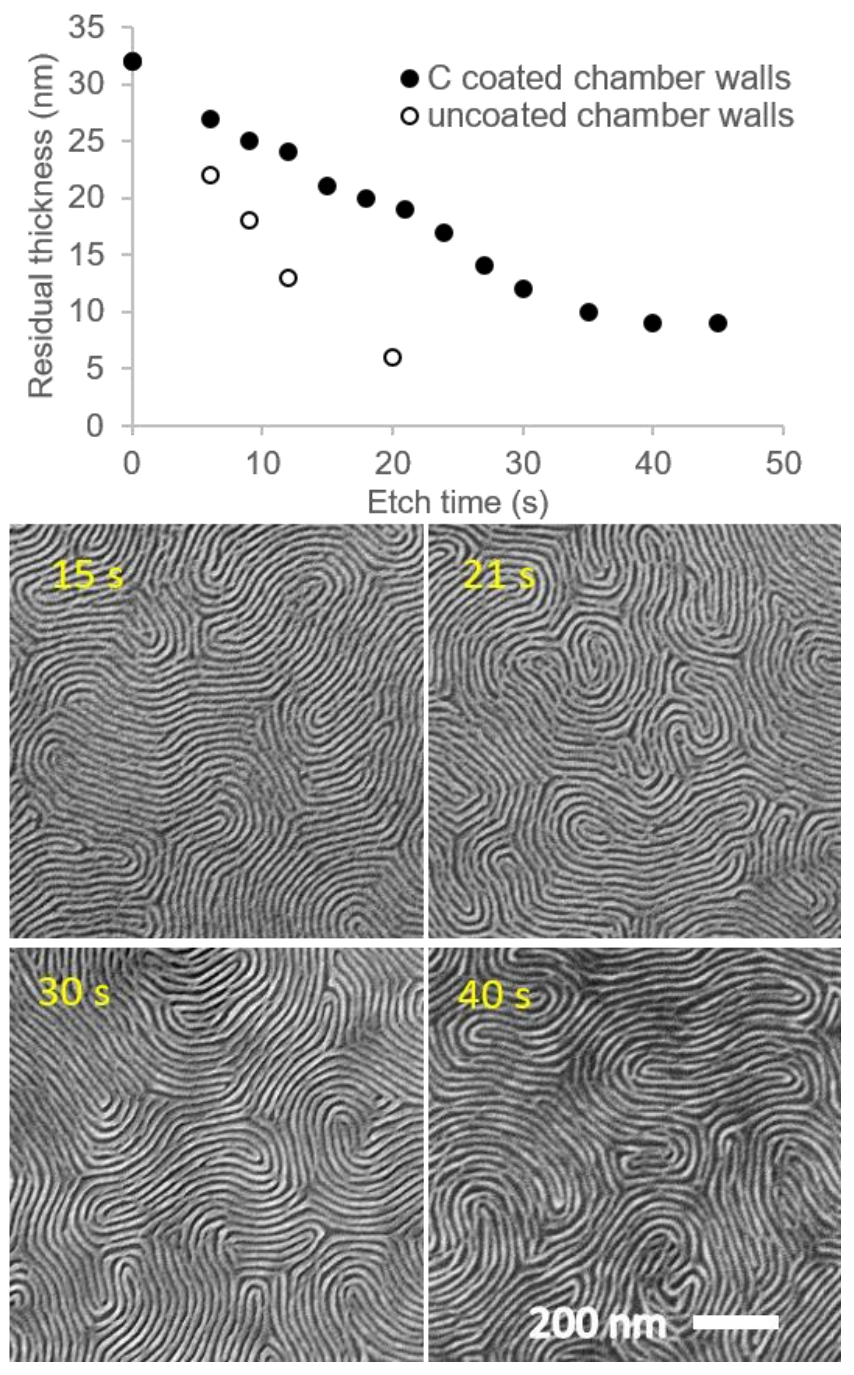

Figure 4: Comparison of the block copolymer residual thickness under a selective $\mathrm{He} / \mathrm{N}_{2} / \mathrm{O}_{2}$ plasma, with and without a carbon protective chamber wall coating (top), and corresponding SEM images of the remaining PDMSB lamellae (below) with a carbon protective chamber wall coating. Plasma etch with $\mathrm{He} / \mathrm{N}_{2} / \mathrm{O}_{2}$ plasma ( $\mathrm{He} 100$ sccm, $\mathrm{N}_{2} 35 \mathrm{sccm}, \mathrm{O}_{2} 15 \mathrm{sccm}, 10 \mathrm{mT}, 250 \mathrm{Ws}, 30 \mathrm{~Wb}$, in $\mathrm{CH}_{4-}$ coated plasma chamber or uncoated chamber) was applied for up to $45 \mathrm{~s}$ (etch times indicated on each SEM image), after topcaot removal with $\mathrm{H}_{2} / \mathrm{N}_{2}$ plasma $\left(\mathrm{H}_{2} 150 \mathrm{sccm}, \mathrm{N}_{2} 50 \mathrm{sccm}, 15 \mathrm{mT}\right.$, $1200 \mathrm{Ws}, 0 \mathrm{~Wb}$, for $33 \mathrm{~s}$ ).

As summarized in the schematic and SEM images reported in Figure 3, selected combinations of plasma dry-etching chemistries for TC and PS phase etch have distinct effects on the quality of the PDMSB-derived lithographic mask. Oxidizing plasma for both TC removal and PS phase removal $\left(\mathrm{Ar} / \mathrm{O}_{2}+\right.$ $\mathrm{CF}_{4} / \mathrm{O}_{2}+\mathrm{Ar} / \mathrm{O}_{2}$ ) leads to smooth lamellae but heterogeneity in mask thickness due to the $\mathrm{CF}_{4}$-based $\mathrm{BT}$ (SEM image 1A). After the $\mathrm{Ar} / \mathrm{O}_{2}$ and $\mathrm{CF}_{4} / \mathrm{O}_{2}$ steps, less damage to the PDMSB mask is achieved with a PS etch in $\mathrm{He} / \mathrm{N}_{2} / \mathrm{O}_{2}$ plasma, but to the expense of higher lamella roughness and with variable feature width (SEM image 1B). Alternatively, interfacial layer removal with a "soft BT" (combination of $\mathrm{Ar} / \mathrm{O}_{2}+\mathrm{He} / \mathrm{CH}_{3} \mathrm{~F} / \mathrm{CF}_{4}+$ $\mathrm{He} / \mathrm{N}_{2} / \mathrm{O}_{2}$ ) improves the homogeneity in lamella width, but local cuts are still visible (SEM image 1'B). TC etch with nonoxidizing $\mathrm{H}_{2} / \mathrm{N}_{2}$ plasma chemistry reveals no interfacial layer but the quality of the mask sees a dramatic influence of the PS etch plasma. TC etch with $\mathrm{H}_{2} / \mathrm{N}_{2}$ followed by PS etch with $\mathrm{Ar} / \mathrm{O}_{2}$ produces a mask with significant bridge formation and collapse of lamellae (SEM image 2A). In contrast, the combination of $\mathrm{H}_{2} / \mathrm{N}_{2}$ plasma to remove the TC (30 - $35 \mathrm{~s}$ ) followed by $30 \mathrm{~s}$ of $\mathrm{He} / \mathrm{N}_{2} / \mathrm{O}_{2}$ plasma in a C-coated ICP chamber to etch the PS phase, provides a thick fully opened silicon-oxy-nitride mask from the PDMSB domains of the BCP. The resulting PDMSB-derived features show regular lamella width and low roughness (SEM image 2B). Therefore, this plasma combination was selected to transfer patterns into the underlying substrate.

As an alternative, promising preliminary results in terms of mask quality were obtained with TC removal by $\mathrm{N}_{2} / \mathrm{H}_{2} 97 / 3$ followed by PS etch with $\mathrm{He} / \mathrm{N}_{2} / \mathrm{O}_{2}$, in spite of localized minor damage to the mask (SEM image 2'B). This approach is particularly relevant for CMOS high volume manufacturing, where high $\mathrm{H}_{2}$ gas content should be avoided.

\section{Pattern transfer into the silicon substrate}

As depicted in Figure 5, the PDMSB lamellae were transferred into the silicon substrate using a $\mathrm{HBr} / \mathrm{O}_{2}$ chemistry, ${ }^{28,29}$ to assess the etch resistance of the modified PDMSB as a mask to pattern amorphous silicon, which is common to many patterning stacks. Bromine-based species are the main etchant here, forming mainly $\mathrm{SiH}_{2} \mathrm{Br}_{2}$ and $\mathrm{SiBr}_{4}$ as volatile products. ${ }^{29}$ The stickiness of most etch by-products can be enhanced by adding some oxygen in the gas mixture so that these sticky byproducts passivate the sidewalls. The transfer plasma is synchronously-pulsed at a pulsing frequency of $1 \mathrm{kHz}$ (cycle times of $1 \mathrm{~ms}$ ) and RF ON times of $200 \mu \mathrm{s}$ ( $20 \%$ duty cycle) to reduce the dissociation of $\mathrm{HBr}$. This results in lower $\mathrm{H}$ radical creation, the latter diffusing into silicon and creating a damage layer, which once removed with diluted HF clean typically reveals a sloped profile in silicon as seen in Figure 5B and C.

A break-through step with a $\mathrm{Cl}_{2}$ or $\mathrm{CF}_{4}$ chemistry is applied to remove the thin $(<2 \mathrm{~nm})$ native oxide layer present at the silicon surface. Transferred patterns present good fidelity with respect to the initial PDMSB mask, as evidenced by either SEM or FIB-STEM techniques (Figure 5), showing dense high aspect-ratio features of $8-9 \mathrm{~nm}$ in width for approx. $45 \mathrm{~nm}$ in depth, thus an aspect-ratio of about 5 obtained with this etch process. Most patterning applications would not require an aspect ratio higher than $3: 1$ in amorphous silicon, therefore this result indicates that the use of the $\mathrm{BCP}$ as a mask to directly pattern amorphous silicon is a viable option. 


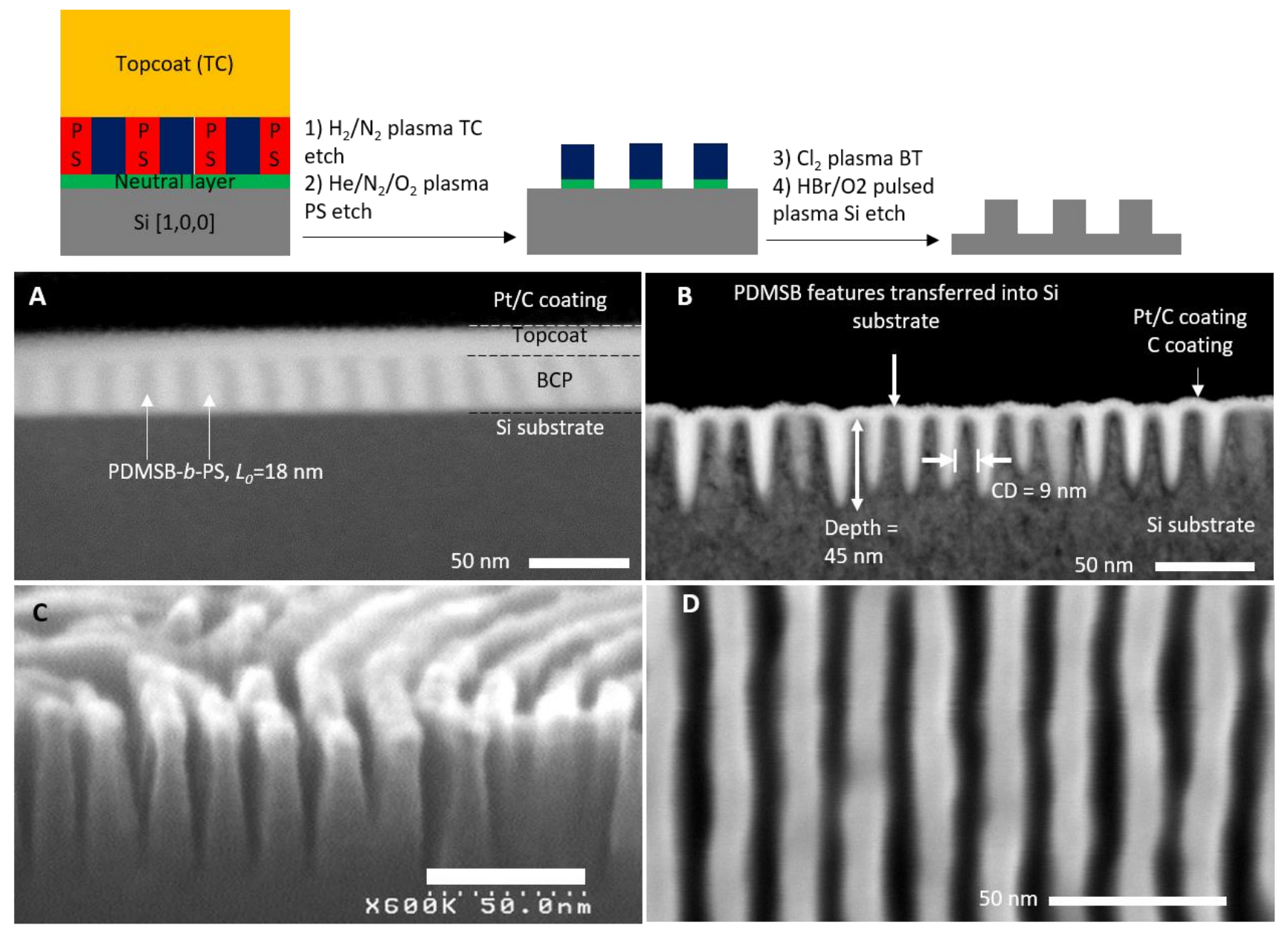

Figure 5: General scheme for the transfer of PDMSB lamellae into a silicon wafer substrate via our full dry etching process (top); FIB-STEM cross-section images of the initial block copolymer stack (A) and of the silicon substrate after transfer of the block copolymer features (B), showing $45 \mathrm{~nm}$ depth for $9 \mathrm{~nm}$ CD features (AR 5); cross-sectional SEM image (C) and SEM topview image (D) of the features transferred into the silicon substrate.

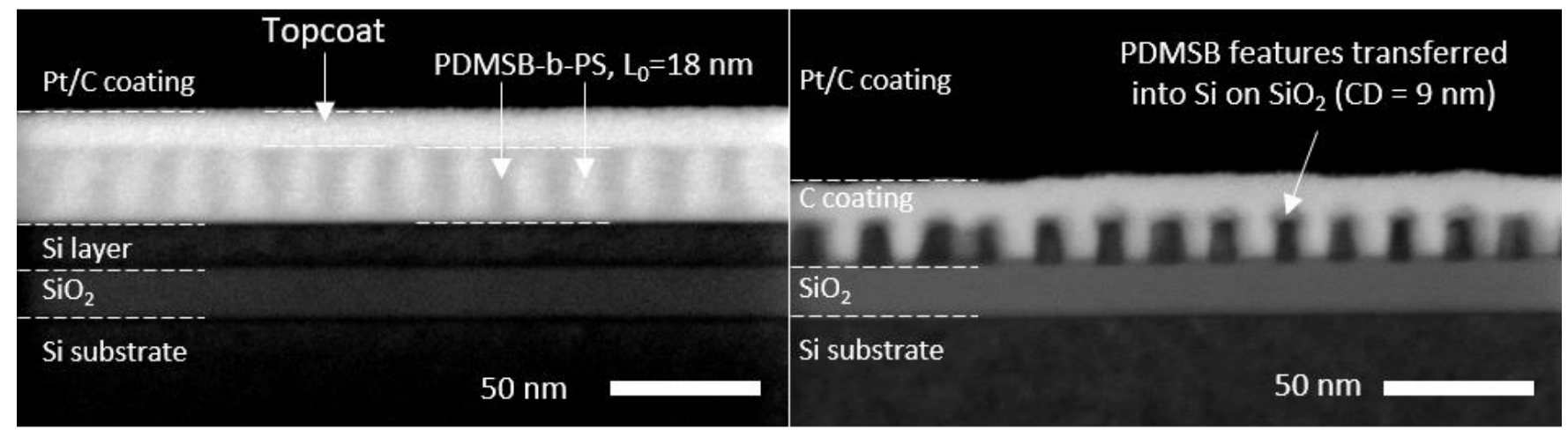

Figure 6: FIB-STEM cross-section of the BCP stack comprising a grafted neutral underlayer and crosslinked neutral topcoat on a SOI substrate with a $15 \mathrm{~nm}$ amorphous $\mathrm{Si}$ layer on a $20 \mathrm{~nm} \mathrm{SiO}$ layer (left) and transferred BCP features after successive dry etching steps, showing $\sim 9 \mathrm{~nm} \mathrm{Si}$ lines on $\mathrm{SiO}_{2}$ (right). 


\section{Pattern transfer into SOI}

The same etch steps were used to pattern a thin crystalline silicon layer $(15 \mathrm{~nm})$ on silica (SOI substrate). Silicon etching was achieved down to the silicon/silica interface without affecting the initial silicon layer thickness. FIBSTEM cross-section images (Figure 6) reveal the presence of a few nm of remaining PDMSB mask at the end of the process, which prevents trimming of the top of the silicon features throughout the pulsed $\mathrm{HBr} / \mathrm{O}_{2}$ plasma etch step. Moreover, the regularity of the etching is much better here thanks to the stop layer on the oxide, avoiding the well-known Aspect Ratio Dependent Etching (ARDE) effect (all trenches have not the exact same CD) as observed on bulk silicon (Figure 5B).

Pattern transfer into other hard-masks relevant to CMOS applications: silicon nitride

The underlayer used to neutralize the interface between the substrate and the BCP is thermally grafted through the reaction of its hydroxyl endgroup to form a metal-oxide bond, ${ }^{8}$ which means that it can easily be grafted onto silicon but also onto $\mathrm{SiO}_{2}, \mathrm{SiN}$ or TiN. As the chemical reaction only affects the polymer chain-end, the grafted underlayer provides an interface with roughly the same characteristics, regardless of the substrate. Consequently, orientation of the BCP lamellae perpendicular to the substrate was not affected by its surface chemistry, confirming that efficient grafting of the neutral underlayer was achieved on these inorganic substrates (Figure 7). Perpendicular orientation of the BCP lamellae was also observed on "spin on carbon" (SOC) modified with thermally grafted neutral underlayer (Figure 7).

The differences observed on the different substrates are due to the fact that the BCP not only "sees" an underlayer due to its low thickness, but rather a combination of the surface energy of the underlayer material and that of the substrate. Thus, the BCP is assembled on substrates exhibiting different "neutrality" conditions, and the self-assembly varies accordingly.

Finally, our BCP patterns could potentially be transferred into a variety of organic or inorganic substrates or hard masks.

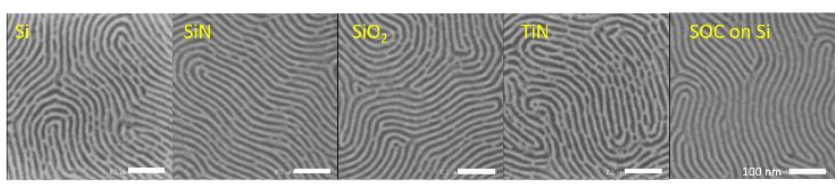

Figure 7: CD-SEM topview images (x $300 \mathrm{k}$, scale bar $100 \mathrm{~nm}$ ) of the block copolymer stack on different substrates: $\mathrm{Si}$ with native $\mathrm{SiO}_{2}$ layer, PECVD SiN, thermally grown $\mathrm{SiO}_{2}$, TiN and spin-oncarbon (SOC) on Si. The substrate surface is made neutral to the
$\mathrm{BCP}$ by thermally grafting the neutral underlayer. Removal of the topcoat layer and partial removal of the PS phase of the BCP was performed by dry-etching $\left(\mathrm{H}_{2} / \mathrm{N}_{2}\right.$ followed by $\mathrm{He} / \mathrm{N}_{2} / \mathrm{O}_{2}$ plasma etching) to reveal the perpendicular orientation of the PDMSB lamellae.

We demonstrate the potential of our stack to transfer lamellar features into other substrates through the example of SiN. SiN is interesting due to its widespread use as a sacrificial hardmask in conventional industrial etch processes. SiN is typically etched with fluorinated gas plasma chemistries, which we found to be damaging to our silicon-based BCP mask (Figure 3). In addition, poor selectivity is expected between the silicon-oxynitride features obtained upon revealing the BCP lamellae and the $\mathrm{SiN}$ substrate. Therefore, we introduced an additional spin on carbon (SOC) layer between the $\mathrm{SiN}$ substrate and the $\mathrm{BCP}$ stack to successively transfer the BCP features into the SOC layer and SOC features into the SiN layer.

Transfer of the BCP features into the SOC layer was achieved using $\mathrm{HBr} / \mathrm{O}_{2}$ gas chemistry (Figure 8), where a continuous wave plasma was applied at relatively low pressure $(5 \mathrm{mT})$ and high source and bias powers $(500 \mathrm{Ws}, 120 \mathrm{~Wb})$. The lower powers $(300 \mathrm{Ws}, 30 \mathrm{~Wb})$ and higher pressures $(15 \mathrm{mT}$ with our pulsed plasma conditions) investigated resulted in the collapse and wriggling of the SOC lines. This is in agreement with previous observations, where the etching conditions should favor sidewall passivation via the deposition of poorly volatile brominated etch products formed during SOC etching. ${ }^{28}$

The transfer of the PDMSB/SOC features into $\mathrm{SiN}$ was achieved with a $\mathrm{Ar} / \mathrm{CH}_{3} \mathrm{~F} / \mathrm{O}_{2}$ gas chemistry ${ }^{30}$ (Ar $200 \mathrm{sccm}$, $\left.\mathrm{CH}_{3} \mathrm{~F} 70 \mathrm{sccm}, \mathrm{O}_{2} 30 \mathrm{sccm}, 10 \mathrm{mT}, 400 \mathrm{Ws}, 50 \mathrm{~Wb}\right)$. Other attempts with an $\mathrm{Ar} / \mathrm{CF}_{4} / \mathrm{CHF}_{3}$ plasma showed poor selectivity, limiting the depth of the transfer into $\mathrm{SiN}$ to approx. $20 \mathrm{~nm}$ before complete etching of the SOC mask. The source power was kept relatively low (400 Ws) to have better control on polymer growth on SOC and avoid wiggling. For an etch process capable of etching lines into the $20 \mathrm{~nm}$ PECVD SiN layer down to the $\mathrm{Si}$ substrate interface, adequate bias powers were in the range of 50 to $90 \mathrm{~Wb}$, and the SOC mask was mostly intact at the end of the etch process applied for $30 \mathrm{~s}$ (remaining SOC lamellae are visible as a light grey shadow on the FIBSTEM image in Figure $8 \mathrm{C}$ and on the tilted SEM image of uncoated sample in $\mathrm{G})$. At the end of the process, very smooth and sub-9 nm SiN lines are obtained. 


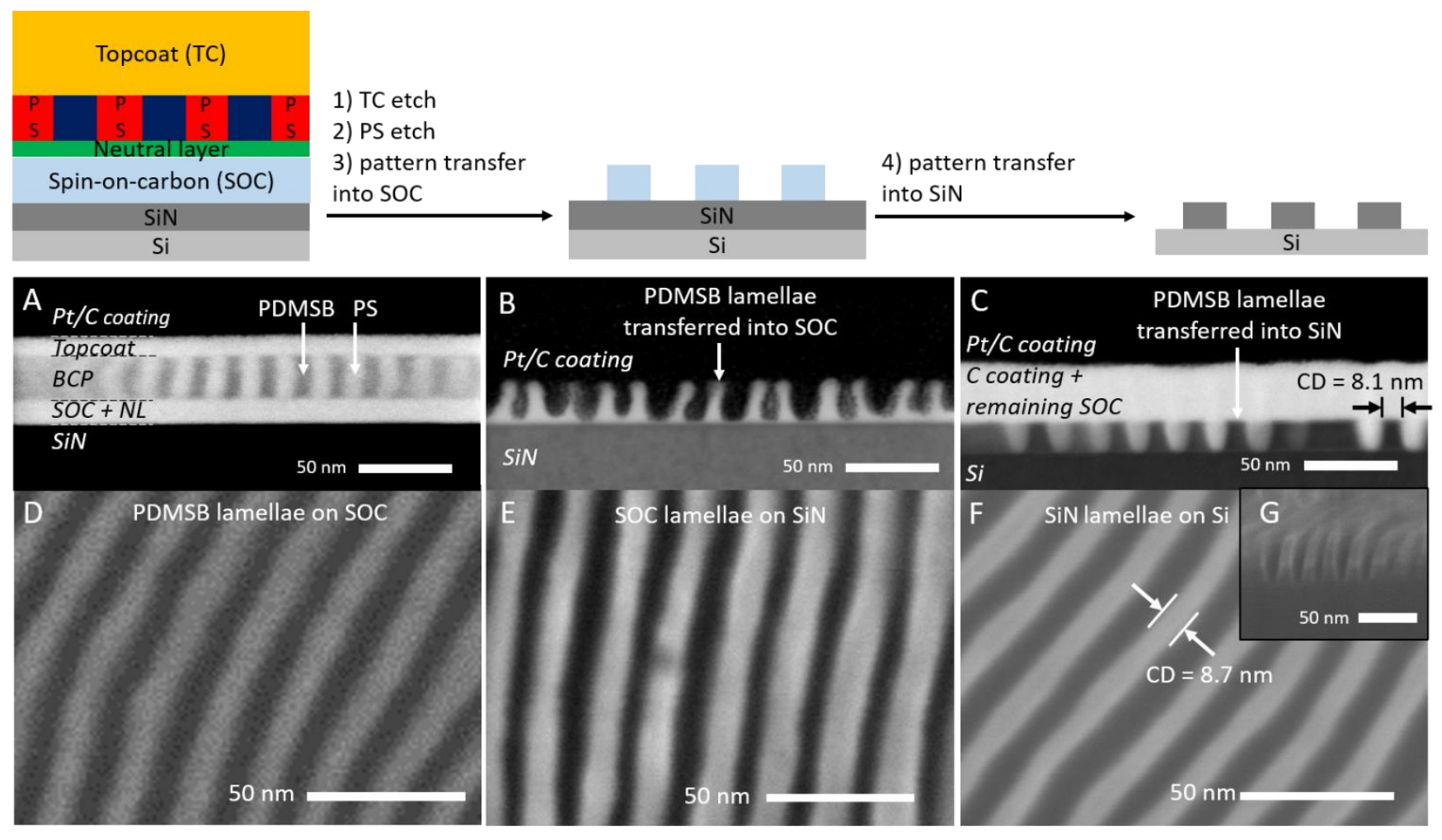

Figure 8: General scheme for the transfer of PDMSB lamellae into SiN via a spin-on-carbon hard mask under a full dry etching process (top); FIB-STEM cross-section images (A,B,C) of the BCP stack comprising a thermally crosslinked SOC, grafted neutral underlayer and crosslinked neutral topcoat on a SiN substrate (A); transferred BCP features into SOC after three successive dry etching steps (B) and into 20 nm of SiN on Si (C); topview SEM images of corresponding uncoated samples, showing PDMSB lamellae on SOC after partial PS etch (D); transferred features into SOC on $\mathrm{SiN}$ (E) and into $\mathrm{SiN}$ with $\mathrm{CD} \sim 9 \mathrm{~nm}(\mathrm{~F}) ; 20^{\circ}$ tilted cross-sectional SEM image evidencing residual SOC lamellae after transfer into $\mathrm{SiN}(\mathrm{G})$. Plasma etch was as follows: TC removal with a $\mathrm{H}_{2} / \mathrm{N}_{2}$ plasma $(33 \mathrm{~s}), \mathrm{PS}$ etch with $\mathrm{He} / \mathrm{N}_{2} / \mathrm{O}_{2}$ plasma $(15$ $\mathrm{s}$ for partial PS removal in D; $30 \mathrm{~s}$ for full PS removal in all other samples); transfer into SOC with a $\mathrm{HBr} / \mathrm{O}_{2} \mathrm{plasma}\left(\mathrm{HBr} 70 \mathrm{sccm}, \mathrm{O}_{2} 30\right.$ sccm, $5 \mathrm{mT}, 500 \mathrm{Ws}, 120 \mathrm{~Wb}, 6 \mathrm{~s}$ ) and transfer into $\mathrm{SiN}$ with a $\mathrm{Ar} / \mathrm{CH}_{3} \mathrm{~F} / \mathrm{O}_{2}$ plasma ( $\mathrm{Ar} 200 \mathrm{sccm}, \mathrm{CH}_{3} \mathrm{~F} 70 \mathrm{sccm}, \mathrm{O}_{2} 30 \mathrm{sccm}, 10 \mathrm{mT}, 400$ $\mathrm{Wb}, 50 \mathrm{Ws}, 30 \mathrm{~s})$. Stripping of the residual SOC layer was carried out with an $\mathrm{O}_{2}$ plasma (50 s) to determine CD in topview image $\mathrm{F}$.

\section{CONCLUSIONS}

In this work, we developed full dry-etching strategies for BCP nanolithography dedicated to microelectronics, as we report pattern transfer of 18 -nm pitch lamellas of a PDMSB- $b$-PS block copolymer into $\mathrm{Si}, \mathrm{SOI}$ and $\mathrm{SiN}$ substrates within practical timeframes (around $30 \mathrm{~s}$ for each etch step). To account for applications requiring etch stops or not, several etch strategies have been proposed. Both an oxidizing $\mathrm{Ar} / \mathrm{O}_{2}$ plasma and a nonoxidizing $\mathrm{H}_{2} / \mathrm{N}_{2}$ plasma can be used to remove the topcoat material of our BCP stack and reveal the PDMSB lamellae. Under $\mathrm{Ar} / \mathrm{O}_{2}$ plasma, an interfacial layer stops the etch process at the top-coat/BCP interface, which provides an etch-stop but also requires an additional $\mathrm{CF}_{4}$-based breakthrough plasma for further etching of the PS component of the BCP. This interfacial layer is not present in $\mathrm{H}_{2} / \mathrm{N}_{2}$. Increasing the ratio of $\mathrm{H}_{2} / \mathrm{N}_{2}$ leads to more profound modification of PDMSB, for which a PS removal chemistry in $\mathrm{He} / \mathrm{N}_{2} / \mathrm{O}_{2}$ rather than $\mathrm{Ar} / \mathrm{O}_{2}$ plasma produces smoother and a more regular PDMSB-derived lithographic mask. Selectivity between PDMSB mask and cSi with a synchronously pulsed $\mathrm{HBr} / \mathrm{O}_{2}$ plasma are also promising for patterning of common aSi at relevant film thickness. Transfer into SiN required an additional SOC hard mask of similar thickness. The PDMSB lamellae were transferred into the SOC layer with an $\mathrm{HBr} / \mathrm{O}_{2}$ plasma, which was in turn transferred into $\mathrm{SiN}$ with a $\mathrm{Ar} / \mathrm{CH}_{3} \mathrm{~F} / \mathrm{O}_{2}$ plasma with excellent selectivities. This work highlights the performance of a silicon-containing blockcopolymer at $18 \mathrm{~nm}$ pitch to pattern relevant hard-mask materials for various applications, including microelectronics.

\section{ASSOCIATED CONTENT}

\section{Supporting Information.}

Topcoat removal by UV and wet etch, alternative BT after $\mathrm{Ar} / \mathrm{O}_{2}$ TC removal, $\mathrm{H}_{2} / \mathrm{N}_{2}$ TC etch-rates with or without $\mathrm{C}$ coating, FIBSTEM image of partially open BCP stack. This material is available free of charge via the Internet at http://pubs.acs.org.

\section{AUTHOR INFORMATION}

\section{* Corresponding Authors}

Gwenaelle Pound-Lana - University of Grenoble Alpes, CNRS, CEA/ LETI Minatec, Grenoble INP, LTM, 38000 Grenoble, France; orcid.org/0000-0003-0569-024;

Email: gpoundlana@gmail.com 
Xavier Chevalier - ARKEMA FRANCE, GRL, BP34 64170

Lacq, France; orcid.org/0000-0001-7397-7849;

Email: xavier.chevalier@arkema.com

Marc Zelsmann - Université Grenoble Alpes, CNRS, CEA/ LETI Minatec, Grenoble INP, LTM, 38000 Grenoble, France; ocid.org/0000-0002-7619-4871;

Email: marc.zelsmann@cea.fr

$†$ IMEC, Kapeldreef 75, 3001 Leuven, Belgium

\section{Author Contributions}

The manuscript was written through contributions of all authors. All authors have given approval to the final version of the manuscript.

\section{Funding Sources}

This work was supported by the REX-7 project from Région Rhône Alpes and BPI France (grant agreement No. DOS0075457/00), by the French RENATECH network and by the French National Research Agency (ANR) within the IMPACT program (contract No. ANR-10-EQPX-33) and the MINOS program (contract No. ANR10-LABX-55-01).

\section{ACKNOWLEDGMENTS}

We thank Celia Nicolet and Christophe Navarro for additional polymer synthesis; Sylvain David for training and assistance with FIBSTEM experiments.

\section{ABBREVIATIONS}

aSi amorphous silicon; BCP block-copolymer; BT breakthrough; $\mathrm{CD}$ critical dimension; CD-SEM critical dimension scanning electron microscopy; CMOS complementary metal-oxide-semiconductor; cSi crystalline silicon; DCTO design-technology co-optimization; DSA directed self-assembly; EUV extreme-UV; FIB focused ion beam; PDMSB poly(1,1-dimethyl silacyclobutane); PS polystyrene; SEM scanning electron microscopy; SOC spin-on-carbon; SOI silicon-on-insulator; STEM scanning transmission electron microscopy; TC topcoat

\section{REFERENCES}

(1) Lai, K.; Liu, C.-C.; Tsai, H.; Xu, Y.; Chi, C.; Raghunathan, A.; Dhagat, P.; Hu, L.; Park, O.; Jung, S.; Cho, W.; Morillo, J.; Pitera, J.; Schmidt, K.; Guillorn, M.; Brink, M.; Sanders, D.; Felix, N.; Bailey, T.; Colburn, M. Design Technology Co-Optimization Assessment for Directed Self-Assembly-Based Lithography: Design for Directed Self-Assembly or Directed Self-Assembly for Design? J. Micro/Nanolithography, MEMS, MOEMS 2017, $16(1), 13502$

(2) Shih, A. J.; Fang, S. Y.; Liu, Y. Y. Guiding Template Design for Lamellar DSA with Multiple Patterning and Self-Aligned Via Process. In IEEE/ACM International Conference on ComputerAided Design, Digest of Technical Papers, ICCAD; 2020; Vol. 2020-November.

(3) Morris, M. A. Directed Self-Assembly of Block Copolymers for Nanocircuitry Fabrication. Microelectron. Eng. 2015, 132, $207-$ 217

(4) Sayan, S.; Marzook, T.; Chan, B.; Vandenbroeck, N.; Singh, A.; Laidler, D.; Sanchez, E. A.; Leray, P.; R. Delgadillo, P.; Gronheid, R.; Vandenberghe, G.; Clark, W.; Juncker, A. Toward Sub-20nm Pitch Fin Patterning and Integration with DSA. In Advances in Patterning Materials and Processes XXXIII; 2016;
Vol. 9779, p 97790R

Park, S.; Lee, D. H.; Xu, J.; Kim, B.; Hong, S. W.; Jeong, U.; Xu, T.; Russell, T. P. Macroscopic 10-Terabit-per-Square-Inch Arrays from Block Copolymers with Lateral Order. Science 2009, 323 (5917), 1030-1033.

Darling, S. B. Directing the Self-Assembly of Block Copolymers. Prog. Polym. Sci. 2007, 32 (10), 1152-1204.

Chevalier, X.; Gomes Correia, C.; Pound-Lana, G.; Bézard, P.; Sérégé, M.; Petit-Etienne, C.; Gay, G.; Cunge, G.; CabannesBoué, B.; Nicolet, C.; Navarro, C.; Cayrefourcq, I.; Müller, M.; Hadziioannou, G.; Iliopoulos, I.; Fleury, G.; Zelsmann, M. Lithographically Defined Cross-Linkable Top Coats for Nanomanufacturing with High- $\chi$ Block Copolymers. ACS Appl. Mater. Interfaces 2021, 13 (9), 11224-11236.

Mansky, P.; Lui, Y.; Huang, E.; Russell, T. P.; Hawker, C. J. Controlling Polymer-Surface Interactions with Random Copolymer Brushes. Science 1997, 275 (5305), 1458-1460.

Aissou, K.; Kwon, W.; Mumtaz, M.; Antoine, S.; Maret, M.; Portale, G.; Fleury, G.; Hadziioannou, G. Archimedean Tilings and Hierarchical Lamellar Morphology Formed by Semicrystalline Miktoarm Star Terpolymer Thin Films. ACS Nano 2016, 10 (4), 4055-4061.

Lo, T. Y.; Krishnan, M. R.; Lu, K. Y.; Ho, R. M. SiliconContaining Block Copolymers for Lithographic Applications. Prog. Polym. Sci. 2018, 77, 19-68.

Legrain, A.; Fleury, G.; Mumtaz, M.; Navarro, C.; Arias-Zapata, J.; Chevalier, X.; Cayrefourcq, I.; Zelsmann, M. Straightforward Integration Flow of a Silicon-Containing Block Copolymer for Line-Space Patterning. ACS Appl. Mater. Interfaces 2017, 9 (49), 43043-43050.

Gusmão Cacho, M. G.; Benotmane, K.; Pimenta-Barros, P.; Bouet, C.; Rademaker, G.; Argoud, M.; Navarro, C.; Tiron, R.; Possémé, N. Selective Plasma Etching of Silicon-Containing High Chi Block Copolymer for Directed Self-Assembly (DSA) Application. J. Vac. Sci. Technol. B 2021, 39 (4), 42801.

Bizouerne, M.; Pargon, E.; Petit-Etienne, C.; Labau, S.; David, S.; Martin, M.; Burtin, P. Low Damage Patterning of In $0.53 \mathrm{Ga}$ 0.47 As Film for Its Integration as N-Channel in a Fin Metal Oxide Semiconductor Field Effect Transistor Architecture . $J$. Vac. Sci. Technol. A 2018, 36 (6), 061305.

Suh, H. S.; Kim, D. H.; Moni, P.; Xiong, S.; Ocola, L. E.; Zaluzec, N. J.; Gleason, K. K.; Nealey, P. F. Sub-10-Nm Patterning via Directed Self-Assembly of Block Copolymer Films with a Vapour-Phase Deposited Topcoat. Nat. Nanotechnol. 2017, 12, 575-581.

Sunday, D. F.; Maher, M. J.; Tein, S.; Carlson, M. C.; Ellison, C. J.; Willson, C. G.; Kline, R. J. Quantifying the Interface Energy of Block Copolymer Top Coats. ACS Macro Lett. 2016, 5 (12), 1306-1311.

Sunday, D. F.; Chen, X.; Albrecht, T. R.; Nowak, D.; Delgadillo, P. R.; Dazai, T.; Miyagi, K.; Maehashi, T.; Yamazaki, A.; Nealey, P. F.; Kline, R. J. Influence of Additives on the Interfacial Width and Line Edge Roughness in Block Copolymer Lithography. 202032 (6), 2399-2407.

Oehrlein, G. S.; Phaneuf, R. J.; Graves, D. B. Plasma-Polymer Interactions: A Review of Progress in Understanding Polymer Resist Mask Durability during Plasma Etching for Nanoscale Fabrication. J. Vac. Sci. Technol. B 2011, 29 (1), 10801.

Thedjoisworo, B.; Cheung, D.; Crist, V. Comparison of the Effects of Downstream H2- and O2-Based Plasmas on the Removal of Photoresist, Silicon, and Silicon Nitride. J. Vac. Sci. Technol. B 2013, 31 (2), 21206.

El Otell, Z.; Šamara, V.; Zotovich, A.; Hansen, T.; De Marneffe, J. F.; Baklanov, M. R. Vacuum Ultra-Violet Emission of CF4and CF3I Containing Plasmas and Their Effect on Low-K Materials. J. Phys. D. Appl. Phys. 2015, 48, 395202.

Sarrazin, A.; Posseme, N.; Pimenta-Barros, P.; Barnola, S.; Gharbi, A.; Argoud, M.; Tiron, R.; Cardinaud, C. PMMA Removal Selectivity to Polystyrene Using Dry Etch Approach. $J$. Vac. Sci. Technol. B 2016, 34 (6), 61802.

Merk, F.; Friedl, R.; Briefi, S.; Fröhler-Bachus, C.; Fantz, U. The Role of Photon Self-Absorption on the $\mathrm{H}(\mathrm{N}=2)$ Density Determination by Means of VUV Emission Spectroscopy and TDLAS in Low Pressure Plasmas. Plasma Sources Sci. Technol. 2021, 30 (6), 065013. 
Delalande, M.; Cunge, G.; Chevolleau, T.; Bézard, P.; Archambault, S.; Joubert, O.; Chevalier, X.; Tiron, R. Development of Plasma Etching Processes to Pattern Sub-15 Nm Features with PS- B -PMMA Block Copolymer Masks: Application to Advanced CMOS Technology . J. Vac. Sci. Technol. B 2014, 32 (5), 51806.

(23) Durand, W. J.; Blachut, G.; Maher, M. J.; Sirard, S.; Tein, S.; Carlson, M. C.; Asano, Y.; Zhou, S. X.; Lane, A. P.; Bates, C. M.; Ellison, C. J.; Willson, C. G. Design of High- $\chi$ Block Copolymers for Lithography. J. Polym. Sci. Part A Polym. Chem. 2015, 53 (2), 344-352.

(24) Yamashita, F.; Nishimura, E.; Yatsuda, K.; Mochiki, H.; Bannister, J. Exploration of Suitable Dry Etch Technologies for Directed Self-Assembly. In Advanced Etch Technology for Nanopatterning; 2012; Vol. 8328.

(25) Omura, M.; Imamura, T.; Yamamoto, H.; Sakai, I.; Hayashi, H. Highly Selective Etch Gas Chemistry Design for Precise DSAL Dry Development Process. In Advanced Etch Technology for Nanopatterning III; 2014; Vol. 9054.

Brihoum, M.; Cunge, G.; Darnon, M.; Gahan, D.; Joubert, O.;
Braithwaite, N. S. J. Ion Flux and Ion Distribution Function Measurements in Synchronously Pulsed Inductively Coupled Plasmas. J. Vac. Sci. Technol. A 2013, 31 (2), 20604.

(27) Fuard, D.; Joubert, O.; Vallier, L.; Bonvalot, M. High Density Plasma Etching of Low K Dielectric Polymers in Oxygen-Based Chemistries. J. Vac. Sci. Technol. B 2001, 19 (2), 447.

(28) Girardot, C.; Böhme, S.; Archambault, S.; Salaün, M.; LatuRomain, E.; Cunge, G.; Joubert, O.; Zelsmann, M. Pulsed Transfer Etching of PS-PDMS Block Copolymers SelfAssembled in $193 \mathrm{Nm}$ Lithography Stacks. ACS Appl. Mater. Interfaces 2014, 6 (18), 16276-16282.

(29) Haass, M.; Darnon, M.; Cunge, G.; Joubert, O. Silicon Etching in a Pulsed HBr/O 2 Plasma. II. Pattern Transfer. J. Vac. Sci. Technol. B 2015, 33 (3), 032202.

(30) Ohtake, H.; Wanifuchi, T.; Sasaki, M. SiN Etching Characteristics of Ar/CH3F/O2plasma and Dependence on SiN Film Density. Jpn. J. Appl. Phys. 2016, 55 (8), 86502. 


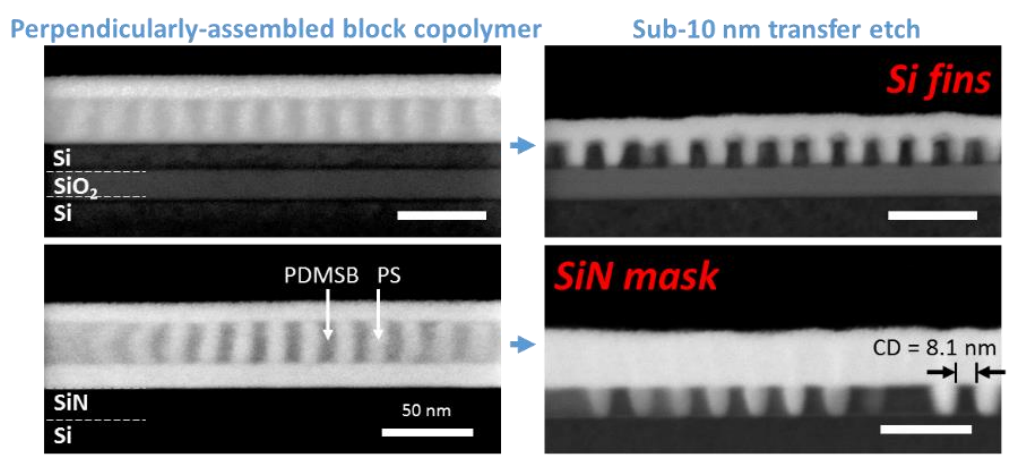

